\title{
Caregivers' quality of life in mild and moderate dementia
}

\author{
Qualidade de vida de cuidadores na demência leve e moderada \\ Raquel Luiza Santos ${ }^{1}$, Maria Fernanda Barroso de Sousa', José Pedro Simões-Neto², \\ Marcela Lima Nogueira', Tatiana T. Belfort ${ }^{1}$, Bianca Torres ${ }^{1}$, Rachel Dias Lopes da Rosa', \\ Jerson Laks ${ }^{1}$, Marcia Cristina Nascimento Dourado ${ }^{1}$
}

\begin{abstract}
Objective: To investigate quality of life (QoL) of caregivers of mild and moderate dementia and the aspects related to QoL. Method: Crosssectional assessment of dyads of people with dementia (PwD) and family caregivers $(n=88)$. Results: Burden $(p<0.05)$ and depressive symptoms $(p<0.001)$ were related to caregivers' $Q$ oL in both stages of dementia. In mild dementia, caregivers' depressive symptoms $(p<0.001)$ and PwD neuropsychiatric symptoms $(p<0.001)$ were related to burden. PwD aberrant motor activity $(p<0.001)$ and anxiety $(p<0.001)$, and caregiver-reported QoL domains of friends $(p<0.001)$ and mood $(p<0.05)$ were related to depressive symptoms. In moderate dementia, selfreported QoL $(p<0.01)$ and anxiety $(p<0.01)$, and PwD anxiety $(p<0.01)$ were related to burden. Caregivers' anxiety $(p<0.001)$ and self-reported $\mathrm{QoL}(\mathrm{p}<0.001)$ were related to depressive symptoms. Conclusion: Burden and depressive symptoms were related to QoL of caregivers of mild and moderate dementia. However, they are driven by different factors according to dementia severity.
\end{abstract}

Keywords: caregivers, quality of life, depression, dementia.

RESUMO

Objetivo: Investigar qualidade de vida (QdV) de cuidadores na demência leve e moderada e aspectos relacionados. Método: Avaliação transversal de pessoas com demência e cuidadores familiares $(n=88)$. Resultados: Sobrecarga $(p<0,05)$ e sintomas depressivos $(p<0,001)$ estavam relacionados à QdV dos cuidadores nos dois estágios da demência. Na demência leve, sintomas depressivos dos cuidadores $(p<0,001)$ e sintomas neuropsiquiátricos dos pacientes $(p<0,001)$ estavam relacionados à sobrecarga. Atividade motora aberrante $(p<0,001)$ e ansiedade do paciente, bem como domínios amigos $(p<0,001)$ e humor $(p<0,05)$ da QdV do cuidador estavam relacionados aos sintomas depressivos. Na demência moderada, $Q d V(p<0,01)$ e ansiedade $(p<0,01)$ do cuidador, e ansiedade do paciente $(p<0,01)$ estavam relacionadas à sobrecarga. Ansiedade $(p<0,001)$ e $Q d V$ dos cuidadores $(p<0,001)$ estavam relacionadas aos sintomas depressivos. Conclusão: Sobrecarga e sintomas depressivos estavam relacionados à QdV de cuidadores de pessoas com demência leve e moderada. Entretanto, estes aspectos estão relacionados a diferentes fatores por severidade da demência.

Palavras-chave: cuidadores, qualidade de vida, depressão, demência.

Quality of life (QoL) has objective and subjective indicators ${ }^{1}$. Among the objective indicators, we may include standard of living, levels of chronic illness, interpersonal relationships with family and friends, and community resources ${ }^{1}$. Subjective indicators are based on personal evaluations of life satisfaction, happiness, adequacy of food, financial resources, housing, family relationships, and feeling valued or fully human ${ }^{1}$.

In dementia, QoL involves cognitive functioning, activities of daily living, social interaction, and psychological well-being ${ }^{2}$. Caregivers face many challenges in caring for people with dementia (PwD), and those may change as the disease progresses $^{3}$. Hoe et al. $^{4}$ suggested that associations between QoL and cognition have been previously observed. Inouye et al. ${ }^{5}$ focused on mild and moderate PwD caregivers. In comparison to the control group, the whole caregiver group negatively evaluated the physical health, energy, mood, memory, self as a whole, and ability to do things for fun dimensions of QoL ${ }^{5}$. Kurz et $\mathrm{al}^{3}{ }^{3}$ found that severe dementia caregivers scored worse than caregivers of people with no cognitive impairment or of people with cognitive impairment and without dementia.

${ }^{1}$ Centro para Doença de Alzheimer e Outros Transtornos Mentais da Velhice, Instituto de Psiquiatria, Universidade Federal do Rio de Janeiro, Rio de Janeiro RJ, Brazil;

${ }^{2}$ Departamento de Sociologia Política, Universidade Federal de Santa Catarina, Florianópolis SC, Brazil.

Correspondence: Raquel Luiza Santos; Rua Constança Barbosa, 140/504; 20735-090 Rio de Janeiro RJ, Brasil; E-mail: raquelluizasantos@yahoo.com.br Conflict of interest: There is no conflict of interest to declare.

Support: This study was supported by Fundação de Apoio à Pesquisa do Estado do Rio de Janeiro (FAPERJ), grant E-26/102.256/2010.

Received 19 June 2014; Received in final form 07 August 2014; Accepted 27 August 2014. 
In this context, this study aims to investigate the factors related to QoL among caregivers of mild and moderate dementia and to further investigate the aspects which might be associated to them. We hypothesized that factors which are possibly related to caregivers' QoL, like caregiver burden and PwD neuropsychiatric symptoms, might differ according to the severity of disease.

\section{METHOD}

\section{Study Design}

This study had a cross-sectional design.

\section{Participants}

Our sample had 88 primary caregivers (21 males) and Alzheimer's disease (AD) outpatients (22 males). Participants attended the outpatient clinic for routine follow-up appointments, and they were consecutively selected, according to the physicians' referrals, from January 2012 to January 2013.

The PwD were diagnosed with possible or probable $\mathrm{AD}$ according to Diagnostic and Statistical Manual of Mental Disorders, Fourth Edition ${ }^{6}$ and National Institute of Neurological and Communicative Diseases and Stroke/Alzheimer's Disease and Related Disorders Association (NINCDS-ADRDA) criteria ${ }^{7}$. People with mild to moderate $\mathrm{AD}$ according to the Clinical Dementia Rating $(\mathrm{CDR})^{8}$ and scores ranging from 13 to 26 in the MiniMental State Examination (MMSE) ${ }^{9}$ were included in the study. In order to ensure the findings were applicable to caring for people with mild or moderate dementia rather than with other clinical problems. PwD with uncontrolled clinical problems, such as hypertension and diabetes, and psychiatric disorders of aphasia, head trauma, alcohol abuse and epilepsy, as defined by the DSM IV-TR criteria were excluded from the study. The primary caregiver was defined as the main person responsible for the PwD care, and we included only informal caregivers (i.e., family members, friends, neighbors or volunteers). We excluded caregivers with a reported history of psychiatric or cognitive disorders. The caregiverPwD dyad had a face-to-face meeting at least once a week, and the caregivers were able to provide detailed information about their care recipients. All of the caregivers had been previously informed of the diagnosis by the psychiatrist. The PwD completed assessments about QoL, cognition, and on their awareness of disease. The caregivers provided information about the PwD (including demographics, the ability to perform activities of daily living - ADL -, and dementia severity) and had QoL, depression, and burden of care assessed.

This study was approved by the Ethics Committee of the Institute of Psychiatry of the Federal University of Rio de
Janeiro (IPUB/UFRJ), and all of the PWD and caregivers received a full description of the study and signed informed consent forms prior to the first interview.

\section{Measurements}

Caregivers' measurements

Quality of life

We applied the Brazilian validated version of the caregiver's QoL (CQoL) $)^{10}$, which comprises 13 items ("physical health", "energy", "mood”, "living situation”, "memory”, "family", "marriage", "friends", "you as a whole", "ability to do chores", "ability to do things for fun", "money" and "life as a whole").

\section{Burden}

We applied the Brazilian validated version of the Zarit Burden Interview $(\mathrm{ZBI})^{11}$, which comprises 22 items that measure the impact of the PwD illness on the caregiver's life. Mood

We applied the Brazilian validated version of the Beck Depression Inventory (BDI) ${ }^{12}$, a 21-item self-report scale that includes a wide range of depressive symptoms, such as feelings of sadness, concerns about the future, suicidal ideation, tearfulness, sleep, fatigue, loss of interest, worries about health, sexual interest, appetite, weight loss and general enjoyment.

\section{Anxiety}

We applied the Brazilian validated version of the Beck Anxiety Inventory (BAI) ${ }^{13}$, a 21-item self-administered instrument that comprises the most frequent anxiety symptoms observed in clinical practice.

\section{PwD measurements}

\section{Severity of dementia}

We applied the full protocol of the Brazilian validated version of the $\mathrm{CDR}^{8}$, in which the possible stages of severity include 0 (no dementia), 0.5 (questionable dementia), 1 (mild dementia), 2 (moderate dementia) and 3 (severe dementia). Quality of life

We applied the Brazilian validated version of the Quality of Life in Alzheimer's disease scale (QoL-AD) ${ }^{10}$. This is the same scale used to assess the caregivers' QoL, but we used both the self-report of the PwD (PQoL) and the caregiver's perspective about the patient $(\mathrm{C}-\mathrm{PQoL})^{10}$. We analyzed the total scores separately.

\section{Cognition}

We applied the Brazilian validated version of the MMSE${ }^{9}$, an instrument that comprises tests of orientation, registration, short-term memory, language use, comprehension and basic motor skills.

\section{Functionality}

In order to measure the PwD functional activities, we applied the Pfeffer Functional Activities Questionnaire (FAQ) ${ }^{14}$. Mood

We applied the Brazilian validated version of the Cornell Scale for Depression in Dementia (CSDD) ${ }^{15}$ to assess mood 
symptoms, physical signs, circadian functions and behavioral symptoms related to depression among the PwD.

\section{Neuropsychiatric symptoms}

The 12-item Brazilian validated version of the Neuropsychiatric Inventory (NPI-12) ${ }^{16}$ was applied in order to assess the presence of delusions, hallucinations, dysphoria, anxiety, agitation/aggression, euphoria, disinhibition, irritability/lability, apathy, aberrant motor activity, nighttime behavior disturbances, and appetite and eating abnormalities.

Awareness of the disease

We applied the Assessment Scale of Psychosocial Impact of the Diagnosis of Dementia (ASPIDD) ${ }^{17}$, a 35-question scale scored based on the discrepancies between the reports of the PwD and the caregivers about awareness of cognitive deficits, social relationships, family relationships, instrumental and basic activities of daily living and affective relationships.

\section{Statistical analysis}

All statistical analyses were performed with SPSS software for Windows version 17.0. The Shapiro-Wilk and Levine tests were used to verify the normal distribution and the variability between the variances, respectively. The parametric variables were described by their mean and standard deviations (SD), and the non-parametric variables were described by their median and interquartile ranges. First, the sociodemographic and clinical characteristics of the caregiver-PwD dyads were analyzed with descriptive statistics. To assess the distinction between mild and moderate dementia, Chi-square tests and ANOVA tests were used.

The relationships between the domains of CQoL ("physical health", "energy”, “mood”, "living situation”, "memory", "family", "marriage”, "friends", "you as a whole”, "ability to do chores", "ability to do things for fun", "money" and "life as a whole") and CDR were investigated using the Chi-square test. Matrices of correlations (Pearson's and Spearman's correlations) were created to investigate the associations between CQoL and age, gender, educational level, duration of the disease, awareness of disease, cognitive function, functional activities, presence of depressive symptoms, and caregiver burden. Based on the significant correlations identified between the CQoL and the other variables, a multivariate linear regression was performed to determine the factors related to the caregivers' QoL.

Next, we built correlation matrices of the ZBI and BDI scores for caregiver-PwD dyads with mild and moderate dementia to identify the associations between these variables and the other clinical variables. The analyses were run separately for the mild and moderate dementia groups. Finally, Stepwise regression models were built to evaluate the factors related to the ZBI and BDI scores.

All significance tests were performed at a two-tailed $\alpha$ level of 0.05 .

\section{RESULTS}

\section{Sociodemographic characteristics \\ Mild dementia group}

The majority of caregivers in this group were women (81.4\%, $\mathrm{N}=35)$, wives (34.9\%; $\mathrm{N}=15)$ and daughters $(30.2 \%$, $\mathrm{N}=13$ ) of PwD. Wives showed a mean age of 67 years old $(\mathrm{SD}=9.27)$ and daughters showed a mean age of 49.6 years old $(\mathrm{SD}=9.66)$.

\section{Moderate dementia group}

The majority of caregivers in this group were women (71.1\%, N=32), mostly daughters (37.8\%, N=17) of PwD. The daughters presented a mean age of 53.3 years old $(\mathrm{SD}=8.77)$.

The sociodemographic characteristics of caregivers and PwD, comparing the characteristics of mild and moderate dementia are shown in Table 1.

\section{Clinical characteristics of caregiver-PwD dyads in the mild and moderate groups}

Moderate PwD were more severely cognitive impaired according to the MMSE $(\mathrm{p}<0.001)$. They also scored higher on the NPI $(p<0.05)$ and on the FAQ $(p<0.001)$. They had a lower QoL as measured by the C-PQoL $(p<0.05)$. Moreover, we found a significant difference in the awareness of the disease $(p<0.05)$. In the moderate dementia group, $71.1 \%$ $(\mathrm{N}=32)$ showed impaired awareness of the disease, whereas in the mild dementia group, $46.5 \%(\mathrm{~N}=20)$ showed unawareness. The differences between the clinical characteristics of the caregiver-PwD dyads according to dementia severity are summarized in Table 2.

\section{Factors related to QoL of caregivers of mild and moderate PwD \\ Univariate analysis}

We did not observe a significant difference between mild and moderate dementia caregivers' QoL ( $\mathrm{f}=0.539$; $\mathrm{p}=0.465)$. Upon analyzing the domains of QoL, there were also no significant differences between mild and moderate dementia caregivers. Mild and moderate dementia caregivers' QoL was correlated with both the age of onset of the PwD $(r=-0.227$; $p<0.05)$ and the duration of the disease $(r=0.259 ; \mathrm{p}<0.05)$. Caregivers' QoL decreases as age of onset and dementia progress.

We found a correlation with depressive symptoms $(\mathrm{r}=-0.638$; $\mathrm{p}<0.001)$, anxiety $(\mathrm{r}=-0.359 ; \mathrm{p}<0.001)$ and burden $(\mathrm{r}=-0.547$; $\mathrm{p}<0.001$ ). Caregivers' QoL is inversely related to their own depressive symptoms, anxiety, and burden.

In addition, both mild and moderate dementia caregivers' QoL is related to the caregivers' perspective of the QoL of the PwD $(r=0.443 ; \mathrm{p}<0.001)$ and PwD's self-reported QoL $(\mathrm{r}=0.245 ; \mathrm{p}<0.05)$. Moreover, we analyzed the relation between caregivers' QoL and each domain of NPI, and found 
Table 1. Sociodemographic characteristics of caregivers and PWD according to dementia severity.

\begin{tabular}{|c|c|c|c|c|}
\hline & Mild (N=43) & Moderate $(\mathrm{N}=45)$ & Total $(\mathrm{N}=88)$ & $\mathrm{p}$ \\
\hline \multicolumn{5}{|l|}{ Caregivers } \\
\hline Females (\%) & 35 (81.4) & $32(71.1)$ & $67(76.1)$ & 0.189 \\
\hline Schooling, mean (SD) & $11.14(3.79)$ & $11.71(3.20)$ & $11.43(3.49)$ & 0.446 \\
\hline \multicolumn{5}{|l|}{ Relationship } \\
\hline Wives (\%) & $15(34.9)$ & $4(8.9)$ & $19(21.6)$ & $0.039 *$ \\
\hline Daughters (\%) & $13(30.2)$ & $17(37.8)$ & $30(34.1)$ & \\
\hline Husbands (\%) & $5(11.62)$ & $4(8.9)$ & $9(10.2)$ & \\
\hline Sons (\%) & $5(11.62)$ & $8(17.8)$ & $13(14.8)$ & \\
\hline Friends (\%) & $2(4.7)$ & $5(11.1)$ & $7(7.9)$ & \\
\hline Other (\%) & $3(7.0)$ & $7(15.5)$ & $10(11.4)$ & \\
\hline \multicolumn{5}{|l|}{ Age } \\
\hline Total, mean (SD) & $59.88(14.74)$ & $58.58(13.04)$ & $59.22(13.83)$ & 0.661 \\
\hline Wives, mean (SD) & $67.0(9.27)$ & $72.8(8.77)$ & $68.2(9.24)$ & 0.281 \\
\hline Husbands, mean (SD) & $76.4(5.94)$ & $79.8(4.11)$ & $77.9(5.21)$ & 0.372 \\
\hline Daughters, mean (SD) & $49.6(9.66)$ & $53.3(8.77)$ & $51.6(9.24)$ & 0.266 \\
\hline Sons, mean (SD) & $44.3(14.01)$ & $46.6(8.52)$ & $46.0(9.55)$ & 0.743 \\
\hline Friends, mean (SD) & $63.7(16.50)$ & $65.7(9.57)$ & $65.1(11.07)$ & 0.806 \\
\hline Other, mean (SD) & $60.0(32.53)$ & $57.4(9.13)$ & $58.1(15.28)$ & 0.860 \\
\hline \multicolumn{5}{|l|}{ PwD } \\
\hline Females (\%) & $26(60.5)$ & $40(88.9)$ & $66(75)$ & $0.002 * *$ \\
\hline Age, mean (SD) & $76.26(6.60)$ & $79.16(7.09)$ & $77.74(6.97)$ & $0.050 *$ \\
\hline Schooling, mean (SD) & $8.33(4.15)$ & $6.82(3.90)$ & $7.56(4.07)$ & 0.083 \\
\hline Married (\%) & $23(53.5)$ & $13(28.9)$ & $36(40.9)$ & $0.016^{*}$ \\
\hline Age of onset, mean (SD) & $72.16(7.67)$ & $74.53(7.64)$ & $73.38(7.70)$ & 0.150 \\
\hline Years of disease, mean (SD) & $4.09(2.51)$ & $4.62(2.47)$ & $4.36(2.49)$ & 0.322 \\
\hline
\end{tabular}

${ }^{*} p<0.05 ;{ }^{*} p<0.01$. PwD: People with dementia; SD: Standard deviation.

that a decrease in mild and moderate dementia caregivers' QoL is related to an increase in the NPI domain of anxiety $(\mathrm{r}=-0.012 ; \mathrm{p}<0.05)$. Caregivers' $\mathrm{QoL}$ is inversely related to the PwD's anxiety symptoms.

The significant and non-significant correlations are shown in Table 3.

\section{Multivariate analyses}

The regression indicated that the caregiver's burden $(\mathrm{p}<0.05)$ and depressive symptoms $(\mathrm{p}<0.001)$ were significantly related to both mild and moderate dementia caregivers' QoL. The final model with the factors associated with the mild and moderate caregivers' QoL explained 49\% of the observed variance $(\mathrm{p}<0.001)$. The adjusted R-squared values and the standardized regression weights are presented in Table 4.

\section{Factors related to burden and depressive} symptoms of caregivers of mild and moderate PwD

Because the caregivers' burden and depressive symptoms were related to the QoL of the caregivers caring for both mild and moderate PWD, we decided to investigate whether

Table 2. Clinical characteristics of caregiver-PwD dyads according to dementia severity.

\begin{tabular}{|c|c|c|c|c|}
\hline & Mild $(\mathrm{N}=43)$ Mean (SD) & Moderate $(\mathrm{N}=45)$ Mean (SD) & Total $(\mathrm{N}=88)$ Mean $(\mathrm{SD})$ & $\mathrm{p}$ \\
\hline \multicolumn{5}{|l|}{ Caregivers } \\
\hline CQoL & $35.95(6.75)$ & $34.80(7.91)$ & $35.36(7.35)$ & 0.465 \\
\hline ZBI & $27.54(18.80)$ & $33.29(18.15)$ & $30.48(18.59)$ & 0.148 \\
\hline $\mathrm{BDI}$ & $7.23(8.52)$ & $9.13(8.67)$ & $8.21(8.60)$ & 0.303 \\
\hline BAI & $9.56(8.58)$ & $10.56(11.69)$ & $10.07(10.25)$ & 0.651 \\
\hline \multicolumn{5}{|l|}{ PwD } \\
\hline PQoL & $32.58(5.73)$ & $30.60(6.76)$ & $31.57(6.32)$ & 0.143 \\
\hline C-PQoL & $29.46(5.45)$ & $26.42(5.66)$ & $27.90(5.73)$ & $0.012^{*}$ \\
\hline MMSE & $21.84(3.17)$ & $16.42(3.77)$ & $19.07(4.41)$ & $0.000 * * *$ \\
\hline CSDD & $7.72(4.81)$ & $9.47(5.46)$ & $8.61(5.19)$ & 0.115 \\
\hline $\mathrm{FAQ}$ & $9.58(6.88)$ & $23.58(6.09)$ & $16.74(9.54)$ & $0.000 * * *$ \\
\hline NPI & $12.51(12.74)$ & $19.93(15.24)$ & $16.31(14.48)$ & $0.015^{\star}$ \\
\hline
\end{tabular}

${ }^{\star} p<0.05 ;{ }^{*}{ }^{*} p<0.001$. SD: Standard deviation; CQoL: Quality of life in Alzheimer's disease scale (caregivers' reports on their own quality of life); ZBI: Zarit Burden Interview; BDI: Beck Depression Inventory; BAl: Beck Anxiety Inventory; PQoL: Quality of life in Alzheimer's disease scale (patients' reports on their own quality of life); C-PQoL: Quality of life in Alzheimer's disease scale (caregivers' reports on patients' quality of life); MMSE: Mini-Mental State Examination; CSDD: Cornell Scale for Depression in Dementia; FAQ: Pfeffer Functional Activities Questionnaire; NPI: Neuropsychiatric Inventory; PwD: People with dementia. 
Table 3. Correlation between CQoL and study variables.

\begin{tabular}{|c|c|c|}
\hline & \multicolumn{2}{|c|}{ CQoL } \\
\hline & $\mathrm{R}$ & $P$ \\
\hline \multicolumn{3}{|l|}{ Caregivers } \\
\hline Gender & -0.141 & 0.191 \\
\hline Age & -0.051 & 0.637 \\
\hline Schooling & -0.081 & 0.456 \\
\hline ZBI & -0.547 & $0.000 * * *$ \\
\hline $\mathrm{BDI}$ & -0.638 & $0.000 * * *$ \\
\hline BAl & -0.359 & $0.001 * \star$ \\
\hline \multicolumn{3}{|l|}{ PwD } \\
\hline Gender & 0.038 & 0.727 \\
\hline Age & -0.184 & 0.086 \\
\hline Schooling & 0.067 & 0.538 \\
\hline Marital Status & -0.105 & 0.329 \\
\hline Age of onset & -0.227 & $0.033^{*}$ \\
\hline Duration of disease & 0.259 & $0.015^{\star}$ \\
\hline PQoL & 0.245 & $0.021 *$ \\
\hline C-PQoL & 0.443 & $0.000 * * *$ \\
\hline MMSE & -0.033 & 0.761 \\
\hline CSDD & -0.060 & 0.581 \\
\hline $\mathrm{FAQ}$ & 0.049 & 0.649 \\
\hline NPI (total) & -0.109 & 0.311 \\
\hline
\end{tabular}

${ }^{*} p<0.05 ;{ }^{* *} p<0.01 ;{ }^{* *} p<0.001$. CQoL: Quality of life in Alzheimer's disease scale (caregivers' reports on their own quality of life); R: Correlation coefficient; P: Significance; ZBI: Zarit Burden Interview; BDI: Beck Depression Inventory; BAl: Beck Anxiety Inventory; PwD: People with dementia; PQoL: Quality of life in Alzheimer's disease scale (patients' reports on their own quality of life); C-PQoL: Quality of life in Alzheimer's disease scale (caregivers' reports on patients' quality of life); MMSE: Mini-Mental State Examination; CSDD: Cornell Scale for Depression in Dementia; FAQ: Pfeffer Functional Activities Questionnaire; NPI: Neuropsychiatric Inventory.

there were differences in the factors related to the caregivers' burden and depressive symptoms by dementia severity.

The regression showed that the caregivers' depressive symptoms $(\mathrm{p}<0.001)$ and $\mathrm{PwD}$ neuropsychiatric symptoms $(\mathrm{p}<0.001)$ were related to the burden experienced by the caregivers of mild PwD. The final model of the factors related to the burden of caregivers of mild dementia explained $52 \%$ of the observed variance $(p<0.001)$. The adjusted R-squared values and the standardized regression weights are presented in Table 5.

The caregivers' global self-reported QoL $(\mathrm{p}<0.01)$, the NPI domain of anxiety $(\mathrm{p}<0.01)$ and caregivers' symptoms of anxiety $(p<0.01)$ were related to the burden of care for caregivers of moderate dementia. The final model of the factors related to the burden for the caregivers of moderate dementia explained $57.1 \%$ of the observed variance $(\mathrm{p}<0.001)$. The adjusted R-squared values and the standardized regression weights are presented in Table 5.
The regression showed that depressive symptoms among the caregivers of mild PwD were related to the NPI domains of aberrant motor activity $(\mathrm{p}<0.001)$ and anxiety $(\mathrm{p}<0.001)$, and caregiver-reported QoL domains of friends $(\mathrm{p}<0.001)$ and mood $(\mathrm{p}<0.05)$. The final model of the factors related to depressive symptoms among the caregivers of mild PwD explained $86.7 \%$ of the observed variance $(\mathrm{p}<0.001)$. The adjusted R-squared values and the standardized regression weights are presented in Table 5 .

Depressive symptoms among the caregivers of moderate PwD were related to the caregivers' anxiety symptoms $(\mathrm{p}<0.001)$ and the caregiver-reported overall QoL $(p<0.001)$ (Table 5). The final model of the factors related to depressive symptoms among the caregivers of moderate PwD explained $68.3 \%$ of the observed variance $(\mathrm{p}<0.001)$. The adjusted R-squared values and the standardized regression weights are presented in Table 5 .

\section{DISCUSSION}

This study aims to investigate the factors related to QoL among caregivers of mild and moderate dementia and to further investigate the aspects which might be associated to them.

Our results showed that the caregivers' burden and depressive symptoms were strongly related with the caregivers' QoL, for the caregivers of both mild and moderate dementia groups. The QoL non-significant result most likely occurred because the sample size was small and there was considerable variation in QoL reported across participants. The QoL scores for the group of caregivers of mild PwD (range 17-49) were included in the range of QoL scores for the group of caregivers of moderate PwD (range 14-51). Both groups had heterogeneous QoL scores, which led to a non-significant result. These results corroborate the results in the literature, which stress the inverse association between caregiver bur$\operatorname{den}^{18,19}$ and depressive symptoms ${ }^{20,21}$ and QoL of caregivers. It has been suggested that caregivers' subjective experiences of depression and burden were more predictive of caregivers' QoL than the objective PwD-related variables, such as the PwD cognitive impairment or functional abilities ${ }^{20}$.

Although our study showed that the same factors were related to the QoL of the caregivers who cared for mild and moderate dementia, the associated factors differed according to the severity of the dementia. For the caregivers of mild dementia, burden was related to the caregiver's

Table 4. Regression model of factors related to QoL among caregivers of mild and moderate dementia.

\begin{tabular}{cccccc}
\hline & $B$ & $\beta$ & $R^{2}$ & Adj. $R^{2}$ & Significance \\
\hline ZBI & $-0.095\left(p=0.014^{\star}\right)$ & -0.241 & 0.490 & 0.478 & $0.000^{* \star \star}$ \\
BDI & $-0.452\left(p=0.001^{\star * *}\right)$ & -0.529 & 0.490 & 0.478 & \\
\hline
\end{tabular}

${ }^{* \star} p<0.05$; ${ }^{* *} p<0.001$. B: Linear coefficient; $\beta$ : Standardized beta coefficient; R²: Coefficient of determination; Adj. R²: Adjusted R-squared values; ZBI: Zarit Burden Interview; BDI: Beck Depression Inventory; QoL: Quality of life. 
Table 5. Regression models of factors related to burden and depressive symptoms among caregivers of mild and moderate dementia.

\begin{tabular}{|c|c|c|c|c|c|}
\hline & $\mathrm{B}$ & $\beta$ & $\mathrm{R}^{2}$ & Adj. $R^{2}$ & Significance \\
\hline \multicolumn{6}{|l|}{ Burden } \\
\hline \multicolumn{6}{|l|}{ Caregivers of mild dementia } \\
\hline $\mathrm{BDI}$ & $0.956(p=0.001 * * *)$ & 0.433 & 0.520 & 0.496 & $0.000 * * *$ \\
\hline NPI & $0.633(p=0.001 * * *)$ & 0.429 & 0.520 & 0.496 & \\
\hline \multicolumn{6}{|l|}{ Caregivers of moderate dementia } \\
\hline CQoL & $-0.899(p=0.002 * *)$ & -0.392 & 0.571 & 0.539 & $0.000 * * *$ \\
\hline NPI anxiety & $1.590\left(p=0.002^{* \star}\right)$ & 0.348 & 0.571 & 0.539 & \\
\hline BAl & $0.551\left(p=0.003^{* *}\right)$ & 0.355 & 0.571 & 0.539 & \\
\hline \multicolumn{6}{|l|}{ Depressive symptoms } \\
\hline \multicolumn{6}{|l|}{ Caregivers of mild dementia } \\
\hline NPI (aberrant motor behavior) & $6.672\left(p=0.000^{* * *}\right)$ & 0.426 & 0.867 & 0.849 & $0.000 * * *$ \\
\hline CQoL (friends) & $-3.640(p=0.000 * * *)$ & -0.368 & 0.867 & 0.849 & \\
\hline NPI (anxiety) & $0.522(p=0.001 * * *)$ & 0.238 & 0.867 & 0.849 & \\
\hline CQoL (humor) & $2.331\left(p=0.013^{\star}\right)$ & 0.216 & 0.867 & 0.849 & \\
\hline \multicolumn{6}{|l|}{ Caregivers of moderate dementia } \\
\hline BAl & $0.383(p=0.000 * \star *)$ & 0.517 & 0.683 & 0.668 & $0.000 * * *$ \\
\hline CQoL & $-0.498(p=0.000 * * *)$ & -0.454 & 0.683 & 0.668 & \\
\hline
\end{tabular}

${ }^{\star} p<0.05 ;{ }^{*} p<0.01 ;{ }^{* \star} p<0.001$. B: Linear coefficient; $\beta$ : Standardized beta coefficient; $\mathrm{R}^{2}$ : Coefficient of determination; Adj. R²: Adjusted R-squared; BDI: Beck Depression Inventory; NPI: Neuropsychiatric Inventory; CQoL: Quality of life in Alzheimer's disease scale (caregivers' reports on their own quality of life); BAl: Beck Anxiety Inventory.

depressive symptoms and PwD neuropsychiatric symptoms. For the caregivers of moderate $\mathrm{PwD}$, the factors related to burden were the caregiver's QoL as a whole and the caregiver's and $\mathrm{PwD}$ anxiety. Among the caregivers of mild dementia, depression (BDI) was related to PwD aberrant motor activity and anxiety, and the caregiver's self-reported QoL in relation to friends and humor. For the caregivers of moderate dementia depressive symptoms (BDI) were related to the caregiver's anxiety and overall QoL. The differences in burden and depressive symptoms between caregivers who care for mild and moderate PwD may be associated with the caregivers' attitudes toward the disease. When the dementia diagnosis is disclosed, caregivers may experience initial difficulties coping with the disease, especially with changes in behavior, which may be a risk factor for increased caregiver burden and depression ${ }^{22}$. Another study suggests that as dementia progresses, the caregivers may experience little success in controlling the clinical aspects of the disease, which may lead them to believe that nothing will change, no matter what action is taken ${ }^{23}$. These feelings of helplessness may be related to emotional distress, burden and depression among the caregivers of moderate dementia, affecting their QoL as a whole. Thus, for caregivers of mild dementia, the burden and depression may be associated with difficulties in managing the disease and adapting to the PwD changes in the behavior, but as the disease progresses, the burden of caregiving and depression may be affected by a decrease in the caregivers' QoL as a whole.

The present study has limitations that are important to acknowledge. First, the lack of a difference in QoL between the caregivers of mild and moderate dementia may be related to the fact that our sample was not randomized. A randomized clinical study would be more appropriate for studying the differences between the groups of caregivers. Second, the instruments should have been administered to the PwD and the caregivers separately to ensure that the study participants were unaware of each other's answers. Third, this study enrolled a small sample, and the fact that many variables were included in the regression analysis may have produced some chance associations. We would argue, however, that the consistency of our observations with those of other studies suggests that this explanation is unlikely ${ }^{18,24}$. Furthermore, we did not assess the caregivers' cognition and personality traits; we only had caregivers' reports about their history of cognitive impairment. Finally, the findings are specific to the caregivers of mild and moderate $\mathrm{AD}$ and may not be generalizable to the caregivers of severe $\mathrm{AD}$. We did not include caregivers of severe $\mathrm{PwD}$ in our research because the care recipients with severe dementia would not be able to respond the instruments applied in our study. It is important for future studies to compare our results with an analysis of more advanced stages of $\mathrm{AD}$.

In conclusion, QoL is a complex concept that includes both subjective and objective components. Therefore, investigating the factors related to the QoL of caregivers of mild and moderate dementia may also produce intricate results. We found that QoL of caregivers of people with mild and moderate dementia is related to burden and depressive symptoms. However, when comparing the caregivers of people with mild dementia and the caregivers of people with moderate dementia, our findings suggest that depressive symptoms and burden are driven by different factors. While a caregiver of mild dementia may have to cope with 
PwD neuropsychiatric symptoms and adapt to the diagnosis of dementia, a caregiver of moderate dementia may have impaired QoL overall because of caretaking tasks.

Our study may be helpful to the improvement of studies about adequate psychoeducational approaches to alleviate caregivers' burden and depressive symptoms and to increase their QoL, considering the main specificities of each clinical stage of dementia, as well as the caregivers' main needs.

\section{References}

1. Keating N, Gaudet N. Quality of life of persons with dementia. J Nutr Health Aging. 2012;16(5):454-6. http://dx.doi.org/10.1007/s12603011-0346-4

2. Whitehouse PJ, Orgogozo JM, Becker RE, Gauthier S, Pontecorvo M, ERzigkeit $\mathrm{H}$ et al. Quality-of-life assessment in dementia drug development. Alzheimer Dis Assoc Disord. 1997;11 Suppl 3:56-60.

3. Kurz X, Scuvee-Moreau J, Vernooij-Dassen M, Dresse A. Cognitive impairment, dementia and quality of life in patients and caregivers. Acta Neurol Belg. 2003;103(1):24-34.

4. Hoe J, Katona C, Roch B, Livingston G. Use of the QOL-AD for measuring quality of life in people with severe dementia-the LASER-AD study. Age Ageing. 2005;34(2):130-5. http://dx.doi.org/ 10.1093/ageing/afi030

5. Inouye K, Pedrazzani ES, Pavarini SCI, Toyoda CY. Perceived quality of life of elderly patients with dementia and family caregivers: evaluation and correlation. Rev Latino-Am Enfermagem. 2009;17(2):187-93. http://dx.doi.org/10.1590/s010411692009000200008

6. American Psychiatric Association. Diagnostic and statistical manual of mental disorders: text revision: DSM-IV-TR. 4th ed. Washington, DC: American Psychiatric Press; 2000.

7. McKhann G, Drachman D, Folstein M, Katzman R, Price D, Stadlan EM. Clinical diagnosis of Alzheimer's disease: report of the NINCDS-ADRDA Work Group under the auspices of department of health and human services task force on Alzheimer's disease. Neurology. 1984;34:939-44. http://dx.doi.org/ 10.1212/wnl.34.7.939

8. Maia AL, Godinho C, Ferreira ED, Almeida V, Schuh A, Kaye J et al. Application of the Brazilian version of the CDR scale in samples of dementia patients. Arq Neuropsiquiatr. 2006;64(2B):485-9. http://dx. doi.org/10.1590/s0004-282×2006000300025

9. Bertolucci PHF, Brucki SMD, Campacci SR, Juliano Y. The mini-mental state examination in a general population: impact of educational status. Arq Neuropsiquiatr. 1994;52(1):1-7.

10. Novelli MMPC, Nitrini R, Caramelli P. Validation of the Brazilian version of the Quality of Life Scale for patients with Alzheimer disease and their Caregivers. Aging Ment Health. 2010;14(5):624-31. http://dx.doi.org/10.1080/13607861003588840

11. Scazufca, M. Brazilian version of the Burden Interview scale for the assessment of burden of care in carers of people with mental illnesses. Rev Bras Psiquiatr. 2002;24(1):12-17. http://dx.doi.org/ 10.1590/S1516-44462002000100006

12. Gorestein C, Andrade L. Validation of a Portuguese version of the Beck Depression Inventory and the State-Trait Anxiety Inventory in Brazilian subjects. Braz J Med Biol Res. 1996;29(4):453-7.
13. Cunha JA. Manual das versões em português das escalas Beck. São Paulo: Casa do Psicólogo; 2001.

14. Pfeffer RI, Kurosaki TT, Harrah CH, Chance JM, Filis S. Measurement of functional activities in older adults in the community. J Gerontol. 1982:37(3):323-9.

15. Carthery-Goulart MT, Areza-Fegyveres R, Schultz RR, Okamoto I, Caramelli P, Bertolucci PH et al. Brazilian version of the Cornell depression scale in dementia. Arq Neuropsiquiatr, 2007;65(\#B):912-5. http://dx.doi.org/10.1590/S0004-282X2007000500037

16. Camozzato, AL, Kochhann R, Simeoni C, Konrath CA, Franz AP, Chaves ML. Reliability of the Brazilian Portuguese version of the Neuropsychiatric Inventory (NPI) for patients with Alzheimer's disease and their caregivers. Int Psychogeriatr. 2008;20(2):383-93. http://dx.doi.org/10.1017/s1041610207006254

17. Dourado MCN, Marinho V, Soares C, Engelhardt E, Laks J. Awareness of disease in Alzheimer's dementia: description of a mild to moderate sample of patient and caregiver dyads in Brazil. Int Psychogeriatr. 2007;19(4):733-44. http://dx.doi.org/10.1017/s1041610207005492

18. Spurlock WE. Spiritual well-being and caregiver burden in Alzheimer's caregivers. Geriatr Nurs. 2005;26(3):154-61. http://dx.doi.org/10.1016/j. gerinurse.2005.03.006

19. Conde-Sala JL, Garre-Olmo J, Turró-Garriga O, López-Pousa S, VilaltaFranch, J. Factors related to perceived quality of life in patients with Alzheimer's disease: The patient's perception compared with that of caregivers. Int J Geriatr Psychiatry. 2009;24(6):585-94. http://dx.doi. org/10.1002/gps.2161

20. Takai M, Takahashi M, Iwamitsu Y, Oishi S, Miyaoka H. Subjective experiences of family caregivers of patients with dementia as predictive factors of quality of life. Psychogeriatrics. 2011;11(2):98-104. http://dx. doi.org/10.1111/j.1479-8301.2011.00354.x

21. Bosboom PR, Alfonso H, Eaton J, Almeida OP. Quality of life in AD: different factors associated with complementary ratings by patients and family carers. Int Psychogeriatr. 2012;24(5):708-21. http://dx.doi. org/10.1017/s1041610211002493

22. Hayes J, Zimmerman MK, Boylstein C. Responding to symptoms of Alzheimer's disease: husbands, wives, and the gendered dynamics of recognition and disclosure. Qual Health Res. 2011;20(8):1101-15. http://dx.doi.org/10.1177/1049732310369559

23. Campbell P, Wright J, Oyebode J, Job D, Crome P, Bentham P et al Determinants of burden in those who care for someone with dementia. Int J Geriatr Psychiatry. 2008;23(10):1078-85. http://dx.doi.org/10.1002/ gps.2071

24. Chappell NL, Reid RC. Burden and well-being among caregivers: examining the distinction. Gerontologist. 2002;42(6):772-80. http://dx.doi.org/10.1093/geront/42.6.772 